Seção Temática: Balanço do Fundeb

Volume 10 - $2020 \mid$ n. 21

\title{
A Política de Fundos e as Responsabilidades Federativas pela Oferta de Educação Básica
}

\author{
Nalú Farenzena \\ Universidade Federal do Rio Grande do Sul (UFRGS), Porto Alegre/RS - Brasil
}

\section{Resumo}

Desde 1997 o Brasil conta com fundos contábeis no financiamento da educação básica, o Fundo de Manutenção e Desenvolvimento do Ensino Fundamental e de Valorização do Magistério (Fundef, de 1997 a 2006) e o Fundo de Manutenção e Desenvolvimento da Educação Básica e de Valorização dos Profissionais da Educação (Fundeb), os quais consideram prioridades dos governos subnacionais e as funções do governo federal na educação básica. O texto apresenta a distribuição dos recursos do Fundeb e das matrículas entre dependências administrativas com o objetivo de discutir a cooperação federativa na oferta e no financiamento da educação no período de vigência dos fundos. São examinadas as matrículas da educação básica e de suas etapas e modalidades educação especial e educação de jovens e adultos. No período, destaca-se a municipalização da educação infantil e do ensino fundamental, a participação discreta do governo da União no Fundeb e descompassos entre dados de matrículas e metas do Plano Nacional de Educação.

Palavras-chave: Fundeb. Fundef. Financiamento da educação. Cooperação federativa na educação. Matrículas na educação básica.

\section{The Funds Policy and the Federative Responsibilities for the Offer of}

\section{Basic Education}

\section{Abstract}

Since 1997, Brazil has counted on accounting funds to finance basic education, the Fund for the Maintenance and Development of Elementary Education and the Valorization of Teaching (Fundef, from 1997 to 2006) and the Fund for Maintenance and Development of Basic Education and Valorization of Education Professionals (Fundeb), which consider priorities of subnational governments and the functions of the federal government in basic education. The text presents the distribution of Fundeb's resources and enrollments among administrative facilities in order to discuss federative cooperation in the provision and financing of education during the period of validity of the funds. Basic education enrollments and their stages and modalities of special education and youth and adult education are examined. During the period, the following stand out: the municipalization of early childhood education and basic education, the discreet participation of the Union government in Fundeb and the mismatches between enrollment data and goals of the National Education Plan.

Keywords: Fundeb. Fundef. Education Funding. Federative cooperation in education. Enrollments in basic education. 
A Política de Fundos e as Responsabilidades Federativas pela Oferta de Educação Básica

\section{Introdução}

O Fundo de Manutenção e Desenvolvimento da Educação Básica e de Valorização dos Profissionais da Educação (Fundeb) foi criado pela Emenda à Constituição (EC) n. 53/2006, no Ato das Disposições Constitucionais Transitórias (ADCT, Art. 60), para vigorar de 2007 a 2020. Substituiu o Fundo de Manutenção e Desenvolvimento do Ensino Fundamental e de Valorização do Magistério (Fundef), vigente de 1997 a 2006 e também objeto do Art. 60 do ADCT (redação dada pela EC n. 14/1996). No ano de 2020, a política de fundos completa 23 anos e sua continuidade é discutida no âmbito do Congresso Nacional, onde emendas constitucionais estão na agenda, visando à instituição do Fundeb em caráter permanente.

O objetivo deste artigo é o de discutir a cooperação federativa na oferta e no financiamento da educação no período de vigência dos fundos, o que é efetuado sem a pretensão de dar conta do amplo leque de suas dimensões, pois as referências se limitam à distribuição dos recursos do Fundeb e de matrículas entre dependências administrativas.

Nas mais de duas décadas em que perdura a política de fundos, diversos foram os fatores intervenientes nas ações públicas voltadas à cobertura e à distribuição da oferta educacional, ou seja, a cooperação federativa na oferta e no financiamento não se restringe a preceitos e a resultados dos fundos. Mesmo assim, por um lado, nas regras dos fundos há disposições normativas sobre prioridades dos governos subnacionais e funções do governo federal na educação básica. Por outro lado, na formulação e na execução da política - com as devidas diferenciações entre Fundef e Fundeb - apresentam-se incentivos, desestímulos e disputas que influenciam a configuração das proporções de matrículas assumidas pelos entes públicos e pelo setor privado. Este é o recorte do texto: identificar regras quanto a prioridades das esferas de governo na oferta e no financiamento da educação presentes nos fundos e examinar indícios da influência da política de fundos na oferta e no financiamento da educação básica por meio de dados de matrículas e de recursos dos fundos.

Os resultados apresentados neste artigo procedem de estudos de vários anos, ancorados em análise documental e de dados numéricos do Fundef, do Fundeb e de matrículas, colhidos em fontes primárias. A exposição é descritiva e fundamentada na compreensão dos fundos como políticas públicas ${ }^{1}$, no viés das regras institucionais e da materialidade da cooperação federativa no financiamento da educação.

O artigo é composto por cinco seções, incluindo esta introdução. No segundo segmento são sumarizados traços da organização federativa da educação quanto a prioridades das esferas de governo na oferta e no financiamento. Na sequência encontra-se uma caracterização do Fundeb, com alguns indicativos de semelhanças e diferenças em relação ao fundo do ensino fundamental e dados dos recursos do Fundeb no período 2007-2018. Na quarta seção, é examinada a evolução das matrículas na educação básica, na educação infantil, no ensino fundamental, no ensino médio, na educação de jovens e adultos e na educação especial; foram feitos registros dos anos de 1996, 2006 e 2018, para um exame pertinente ao contexto dos fundos contábeis. A parte final tem caráter de síntese, sendo reiterados aspectos relativos à distribuição de matrículas, aos recursos dos fundos e a desafios na garantia do direito à educação: respectivamente, a municipalização da educação

1 Em termos teórico-metodológicos da análise de políticas há inspiração em elementos do conceito de trajetória de reformas e de políticas de Bezes e Palier (2018). 
infantil e do ensino fundamental, a participação residual e discreta do governo da União no Fundef e no Fundeb e graves descompassos entre dados de matrículas e metas do Plano Nacional de Educação.

\section{Responsabilidades (Inter)Federativas na Educação Básica²}

A cooperação federativa na educação fundamenta-se na competência comum das esferas de governo - União, estados, Distrito Federal (DF) e municípios - de garantir os meios de acesso à educação, à cultura e à ciência, conforme estabelecido no Art. 23 da Constituição da República (ARAUJO, 2010). A edição de normas de âmbito nacional que definam e articulem sistema nacional de educação, cooperação federativa na educação e regime de colaboração entre os sistemas de ensino está pendente, mesmo passados mais de 30 anos da promulgação da Carta Constitucional. Mesmo assim, neste texto, as atribuições prioritárias das esferas de governo na oferta e no financiamento da educação básica, por exigirem ações cooperativas, serão tratadas como parte da política de cooperação federativa no setor, com suas lacunas e omissões.

A legislação nacional, da qual se destacam a Constituição da República e a Lei de Diretrizes e Bases da Educação Nacional (LDB - Lei n. 9.394/1996), designa a educação infantil como prioridade dos municípios, o ensino médio como prioridade dos estados e o ensino fundamental como etapa a ser priorizada por ambos, municípios e estados; ressalvase que as etapas são prioridades e, como tal, podem ser extrapoladas, desde que cumpridas condições que são diferentes para estados e municípios. As incumbências da União são as de organizar e manter a rede pública federal e de prestar assistência financeira e técnica aos governos subnacionais, para equalizar oportunidades e garantir padrão mínimo de qualidade do ensino ${ }^{3}$. Na educação básica, as atribuições de prioridade por etapas da educação e o papel da União têm repercussões diretas em dois âmbitos da atuação estatal tratados neste artigo: a oferta e o financiamento. As proporções de matrículas - dado escolhido para tratar da oferta - do primeiro nível da educação assumidas pelas esferas de governo serão detalhadas mais adiante neste texto.

Quanto à dimensão do financiamento da educação na atuação do Estado na área, a Constituição da República preceitua, para as esferas de governo, a aplicação de parte de sua receita líquida de impostos em manutenção e desenvolvimento do ensino - 18\% é a parcela do governo federal ${ }^{4}$ e $25 \%$ a dos estados, Distrito Federal e municípios (Art. 212). Essa é a principal fonte, seguida pelo salário-educação, contribuição social recolhida mensalmente por empresas e calculada sobre o total de remunerações dos empregados segurados. Deve ser destinada exclusivamente ao financiamento da educação básica pública, com parcelas

2 Este segmento do texto teve como referências: Farenzena (2006; 2015; 2018); Farenzena e Luce (2013; 2014).

3 Quanto à atuação direta da União na educação, vale lembrar que a rede federal de ensino é composta majoritariamente por universidades, institutos federais de educação, ciência e tecnologia e centros federais de educação tecnológica. As prioridades na oferta são, de fato, a educação superior e o ensino técnico. $O$ ensino técnico é o único segmento em que a rede federal tem mais representatividade na educação básica (suas matrículas representaram $20 \%$ do total e $35 \%$ das redes públicas em 2018).

4 Com a Emenda n. 95/2016 à Constituição (teto de gastos primários da União), a vinculação de 18\% ficou suspensa por 20 anos. Em 2017, ainda valeu a regra de 18\% e, a partir de 2018, o mínimo a ser aplicado em MDE corresponde "[...] aos valores calculados para as aplicações mínimas do exercício imediatamente anterior" (Art. 110, inciso II), corrigidos pelo Índice de Preços ao Consumidor Amplo (IPCA), ou índice que venha a substituí-lo, considerando o período de doze meses encerrado em junho do exercício anterior ao da lei orçamentaria. 
repartidas entre os entes da federação - a parcela federal representa, atualmente, $40 \%$ e, as cotas estaduais e municipais, $60 \%$ dos recursos. O montante do governo federal financia diversos programas de assistência técnico-financeira aos governos subnacionais, como os de alimentação escolar, dinheiro direto na escola, transporte escolar e livros didáticos.

Quanto à partilha do financiamento público da educação entre as esferas de governo, as proporções são as seguintes: União - $29 \%$, estados e Distrito Federal - $33 \%$, municípios - 38\% (INEP, 2018) $)^{5}$. É uma configuração bem diferente daquela da repartição do bolo tributário do País: em 2018, da receita tributária disponível, 55\% foi apropriada pela União, seguida pelos estados, com $25 \%$ e, por último, os municípios, com $20 \%$ (AFONSO; CASTRO, 2019). A fatia bem maior do bolo tributário apropriada pela União é um entre os fatores que explicam os preceitos - tal como os que constam no Plano Nacional de Educação vigente e as reivindicações de aumento significativo da alocação de recursos federais na educação. Proporções tão diferentes entre os dois indicadores, sem suficientes mecanismos de equalização, levam à persistência de um quadro injusto em que as condições para o acesso e a permanência na escola ficam dependentes das capacidades de financiamento de cada ente, lesando o princípio da garantia de sua igualdade.

É de reiterar, para fechar esta parte do texto, que a cooperação federativa no financiamento da educação é efetivada por intermédio de políticas com transferências intergovernamentais de recursos, sendo a principal o Fundo de Manutenção e Desenvolvimento da Educação Básica e de Valorização dos Profissionais da Educação (Fundeb), vigente desde 2007, objeto de descrição na sequência.

\section{Do Fundef ao Fundeb 6}

O Fundeb, assim como era o Fundef, tem natureza contábil, funciona no âmbito de cada unidade da federação e é mecanismo redistributivo de recursos entre governo estadual e municípios, com movimentação automática e periódica de recursos. A redistribuição abrange parte da receita resultante de impostos vinculada à manutenção e desenvolvimento do ensino (MDE). Os objetivos do Fundeb são os de manter e desenvolver a educação básica pública e valorizar os trabalhadores da educação, incluindo sua condigna remuneração. De modo concreto, a valorização dos trabalhadores do setor foca o magistério, pois $60 \%$ dos recursos de cada ente deve ser alocada à remuneração dos profissionais do magistério em efetivo exercício. De modo implícito, o Fundeb visa também promover maior aproximação na disponibilidade de recursos entre os entes subnacionais da Federação brasileira. O Fundef tinha objetivos semelhantes, porém se restringia ao ensino fundamental. Além disso, os dois fundos também se diferenciam pelos itens da receita líquida de impostos que os compõem e as suas proporções de retenção. Em ambos há complementação da União, com regras estabelecidas na legislação, porém, os critérios para a complementação ao Fundef nunca

5 Estes dados referem-se a gasto público em educação e foram retirados da publicação Relatório do segundo ciclo de monitoramento das Metas do Plano Nacional de Educação. O INEP estima dois indicadores para monitorar a meta 20 do PNE: gasto público em educação e gasto público em educação pública. No gasto público em educação são computados despesas e restos a pagar pagos, gastos tributários, gastos com receitas parafiscais e subsídios em educação; para evitar dupla contagem, as transferências entre entes federativos são computadas para o ente transferidor.

6 Parte do conteúdo deste item baseia-se em aspectos das descrições do Fundeb e do Fundef trabalhados em Farenzena $(2015 ; 2014 ; 2012)$. 
foram respeitados no período de sua vigência. Desse modo, a complementação da União ao Fundeb sempre foi muito maior do que ao Fundef.

O Fundeb abrange a educação infantil, o ensino fundamental e o ensino médio, bem como modalidades dos mesmos. Na prática, são 26 fundos estaduais e o do Distrito Federal. Em cada estado há contribuição contínua, ao longo do ano fiscal, do governo estadual e das prefeituras, oriunda de uma proporção significativa dos recursos da receita resultante de impostos vinculada à MDE (ver Quadro 1). A proporção de recursos a ser destinada a cada ente é dada por um coeficiente, sendo este o resultado da divisão das matrículas de cada rede pelo total de matrículas, havendo ponderações para estas matrículas (por etapas, modalidades e certas situações de oferta - urbano ou rural, tempo parcial ou integral, entre outras). O cômputo de matrículas de cada ente respeita as prioridades mencionadas na seção anterior deste artigo: para os estados, são consideradas as matrículas dos ensinos fundamental e médio e, para os municípios, as da educação infantil e do ensino fundamental. Contam as matrículas nas redes públicas e, mediante alguns critérios, matrículas de instituições conveniadas com os poderes públicos - as de creche e pré-escola para os municípios e as de educação especial e formação por alternância para os estados e os municípios. No que diz respeito ao cômputo de matrículas de pré-escola de instituições conveniadas com prefeituras, a Lei 11.494/2007 previu, inicialmente, que seria admitida por quatro anos (até 2010), prazo prolongado, na sequência, até 2016 e, por fim, até a universalização da pré-escola, conforme previsto no PNE 2014-2024.

Há também a complementação da União - que deve corresponder a, no mínimo, 10\% dos recursos de contribuição dos governos subnacionais -, destinada a fundos estaduais cujos recursos próprios não permitem atingir o valor mínimo nacional por aluno. Esse valor mínimo decorre da própria distribuição da complementação da União. No Fundef, o valor mínimo por aluno deveria ser o quociente da divisão do total dos recursos estaduais, municipais e do DF pelo total de matrículas do ensino fundamental de todo o País (matrículas do ano anterior e estimativas de novas $)^{7}$. Em termos de valor mínimo da complementação da União, essa regra do Fundef, se aplicada ao Fundeb, teria permitido estipular valores por aluno por ano maiores do que os efetivados. O problema, como já dito, é que essa fórmula foi descumprida no prazo de vigência do Fundef $^{8}$. Cabe destacar, ainda, que a Emenda à Constituição n. 14/1996 estabeleceu que deveriam ocorrer ajustes progressivos de contribuições da União e dos governos subnacionais ao Fundef, a fim de garantir valor mínimo anual por aluno que correspondesse a padrão de qualidade de ensino definido nacionalmente. Esse parâmetro foi reiterado na Lei n. 9.424/1996, sendo indicados critérios a levar em conta para definições sobre padrões de qualidade do ensino. Tampouco essa determinação foi efetivada.

O Fundeb teve implantação gradativa, tornando-se pleno em 2010, com o cômputo de todas as matrículas e todos os recursos. Os itens da receita de impostos dos governos estaduais, municipais e do DF que são vinculados à manutenção e desenvolvimento do ensino, distinguindo-se aqueles que constituem o Fundeb, constam no Quadro 1.

7 Conforme disposições da Lei n. 9.424/1996 (regulamentação do Fundef), o valor mínimo anual por aluno foi estabelecido em $\mathrm{R} \$ 300,00$ para o primeiro ano de vigência do Fundo.

8 A observância dos valores mínimos de cada ano para a complementação da União permaneceu sendo cobrada por ações no Judiciário. Desde 2013 ocorre recebimento de recursos dos precatórios do Fundef por estados e municípios (ver TCU, 2020). 
Quadro 1 - Receitas da manutenção e desenvolvimento do ensino e do Fundeb, dos estados, DF e municípios, por origem

\begin{tabular}{|c|c|c|c|}
\hline ENTE FEDERADO & ORIGEM & INTEGRANTES DO FUNDEB & $\begin{array}{c}\text { NÃO INTEGRANTES } \\
\text { DO FUNDEB }\end{array}$ \\
\hline \multirow{2}{*}{$\begin{array}{l}\text { ESTADOS E } \\
\text { DISTRITO } \\
\text { FEDERAL }\end{array}$} & RECEITAS PRÓPRIAS & $\begin{array}{l}\text { ITCMD } \\
\text { ICMS } \\
\text { IPVA }\end{array}$ & \\
\hline & $\begin{array}{c}\text { RECEITAS DE } \\
\text { TRANSFERÊNCIAS }\end{array}$ & $\begin{array}{c}\text { FPE } \\
\text { Compensação desoneração } \\
\text { ICMS } \\
\text { Cota Parte do IPI-Exportação }\end{array}$ & $\begin{array}{c}\text { IRRF } \\
\text { Cota Parte do IOF ouro }\end{array}$ \\
\hline \multirow{3}{*}{$\begin{array}{l}\text { MUNICÍPIOS E } \\
\text { DISTRITO } \\
\text { FEDERAL }\end{array}$} & RECEITAS PRÓPRIAS & & $\begin{array}{c}\text { IPTU } \\
\text { ITBI } \\
\text { ISS } \\
\text { ITR, caso tenha optado } \\
\text { por cobrar e fiscalizar }\end{array}$ \\
\hline & \multirow{2}{*}{\multicolumn{2}{|c|}{$\begin{array}{c}\text { FPM } \\
\text { Cota Parte do IPI-Exportação } \\
\text { Cota Parte do ICMS } \\
\text { Cota Parte do IPVA } \\
\text { Cota Parte do ITR, caso não } \\
\text { tenha optado por cobrar e } \\
\text { fiscalizar } \\
\text { Compensação desoneração } \\
\text { ICMS }\end{array}$}} & $\begin{array}{c}\text { IRRF } \\
\text { Cota Parte do IOF ouro }\end{array}$ \\
\hline & & & \\
\hline
\end{tabular}

Fonte: Retirado de Tanno (2017).

Do quadro acima, cumpre esclarecer que há dedução de $20 \%$ de uma parcela dos itens da receita líquida de impostos que integram o Fundeb, as quais são destinadas diretamente para as contas de cada Fundo contábil estadual. Assim, há contribuição de $20 \%$ de todos os entes e divisão dos recursos com base no coeficiente de cada ente, dado pelo número de matrículas computadas no Censo Escolar da Educação Básica do ano anterior ${ }^{9}$. Os recursos são creditados na conta Fundeb de cada município e na conta Fundeb do estado. Dos itens de receita resultante de impostos do Fundeb, o ICMS tem a maior proporção (59,2\% em 2018), seguido pelos fundos de participação, FPE e FPM (24\% em 2018), segundo dados da Secretaria do Tesouro Nacional (STN, 2018).

A evolução dos recursos, entre 2007 e 2018, consta no Gráfico 1.

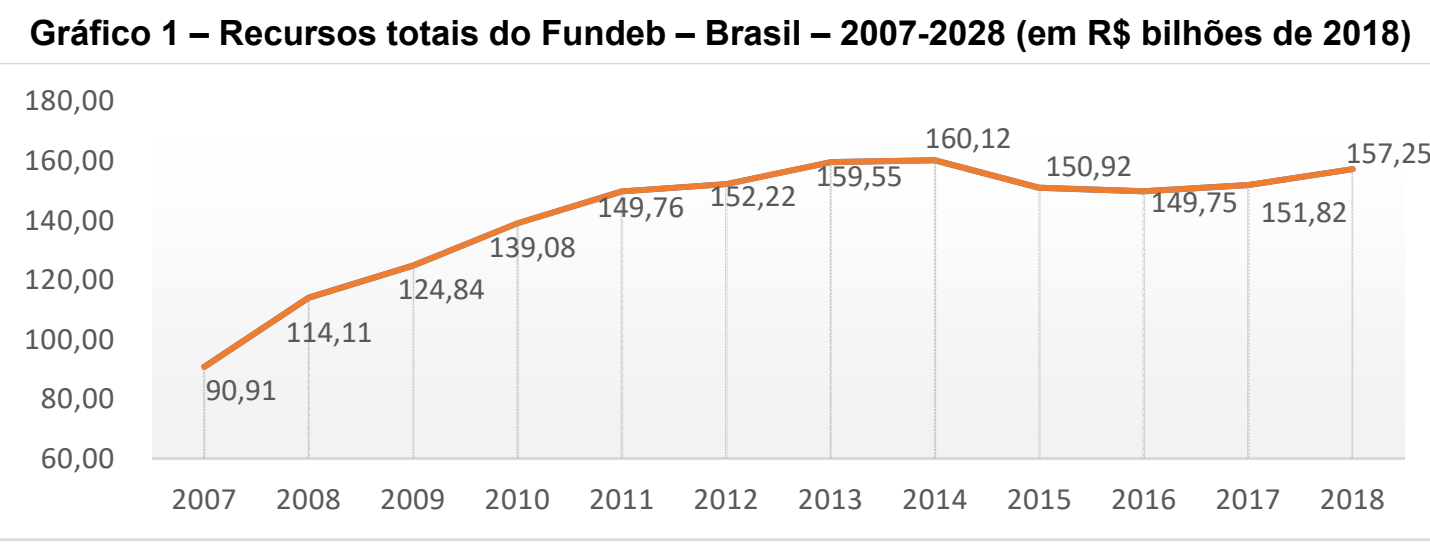

Fonte: Portarias do ajuste anual do Fundeb (ver referências do Apêndice). Nota: valores atualizados pelo INPC de dez. 2018.

9 Contam as matrículas nas redes públicas e matrículas de instituições conveniadas com os poderes públicos - de creche, pré-escola, educação especial e formação por alternância -, estas últimas tendo em conta uma série de critérios. 
Em 2010, quando o Fundeb se tornou pleno ${ }^{10}$ - com a integralização dos recursos seus recursos foram de $\mathrm{R} \$ 139,08$ bilhões, chegando a $\mathrm{R} \$ 160,12$ bilhões em 2014 (15\% a mais); em 2015 e 2016, como resultado da crise econômica, houve diminuição em relação a 2014 , com $\mathrm{R} \$ 150,92$ bilhões e $\mathrm{R} \$ 149,75$ bilhões, respectivamente, ou seja, em torno de $6 \%$ menos que 2014. Os recursos de 2018, de $R \$ 157,25$ bilhões, também ficam num patamar inferior aos de 2014. A variação dos valores mínimos anuais por aluno do Fundeb foi afetada pelos movimentos dos recursos, entretanto, queda de um ano para outro, em valor real, ocorreu somente em 2015. Isso decorre do movimento das matrículas, as quais, considerando o total da educação básica pública, decresceram. A proporção de recursos do Fundeb em relação ao PIB, nos anos de 2010 a 2018, ficou em 2,2\% ${ }^{11}$.

A complementação da União acompanhou o movimento dos recursos estaduais, municipais e do DF. Beneficiou, no período, os seguintes estados: Amazonas, Pará, Alagoas, Bahia, Ceará, Maranhão, Paraíba, Pernambuco, Piauí e Rio Grande do Norte. Como nunca foi aplicado mais do que $10 \%$ dos recursos dos estados e municípios, essa complementação também teve queda em valores reais nos anos de 2015 e 2016.

Para ilustrar o montante da contribuição da União, o Gráfico 2 registra dados do ano de 2018.

\section{Gráfico 2 - Total de recursos, recursos dos estados e municípios (E+M) e complementação da} União no Fundeb - Brasil - 2018 (em R \$ bilhões)

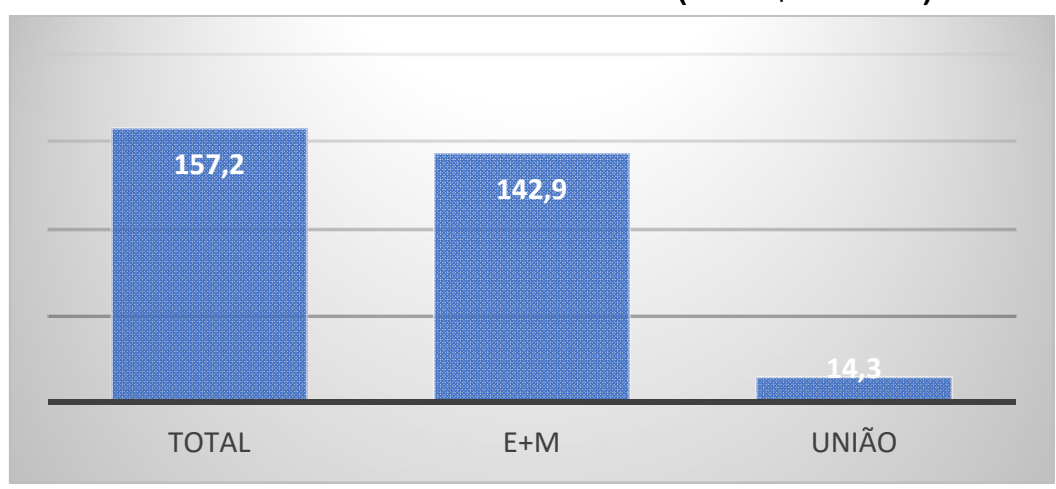

Fonte: Portaria MEC n. 46, de 29/04/2019 (ajuste anual Fundeb exercício 2018).

A complementação, em 2018, limitou-se ao mínimo de $10 \%$ dos recursos estaduais, municipais e distrital. Em relação ao PIB, representa irrisórios $0,2 \%$. Mesmo que tenha sido mantida a complementação no nível mínimo e que este possa ser chamado de discreto, cabe lembrar que a complementação ao Fundef era residual: em 2006, por exemplo, representou apenas $1 \%$ dos recursos dos estados, municípios e DF e só beneficiou o Pará e o Maranhão.

O Fundeb possibilitou equiparação mais expressiva na capacidade de gasto dos entes, o que pode ser examinado por meio dos valores anuais por aluno (VAA) dos fundos ${ }^{12}$. Em

10 A implantação do Fundeb foi progressiva. Em 2009 foram integralizados os recursos dos governos subnacionais e passou a ser computado o total de matrículas. A partir de 2010, a proporção da complementação da União passou a ser de, no mínimo, 10\% dos recursos dos estados, DF e municípios, quando, nos anos anteriores, havia sido fixada em valores monetários mínimos: 2 bilhões, 3 bilhões e 4,5 bilhões em 2007, 2008 e 2009, respectivamente (conforme a Lei n. 11.494/2007, de regulamentação do Fundeb).

11 Os dados de recursos/PIB foram calculados pela autora, tendo como fontes o IBGE (PIB) e FNDE (recursos do Fundeb).

12 Uma descrição de efeitos redistributivos do Fundef e do Fundeb tendo em conta os anos de 2006 a 2012, na perspectiva interestadual, encontra-se em Farenzena (2015). Na mesma perspectiva, e de modo mais 
2006, no Fundef, dez estados tinham um VAA superior em $100 \%$ ao VAA mínimo nacional. No primeiro ano do Fundeb havia diferenças de mais de $50 \%$ entre o valor mínimo nacional e o VAA de dez estados, mas em apenas três a decalagem era maior que $100 \%$; em 2018 , o VAA de apenas dois estados foi maior que $40 \%$ do mínimo nacional do Fundeb - Roraima, com $59 \%$, e Rio Grande do Sul, com $45 \%{ }^{13}$. Valores por aluno de quatro estados constam no Gráfico 3, a fim de ilustrar o movimento de equiparação, restrito ao âmbito do Fundeb. Gráfico 3 - Valor anual por aluno das séries iniciais do ensino fundamental urbano pós ajuste anual
do Fundeb - Pará, Mato Grosso, Rio Grande do Sul e São Paulo - 2006, 2010 e 2018 (em R\$ 1,00)

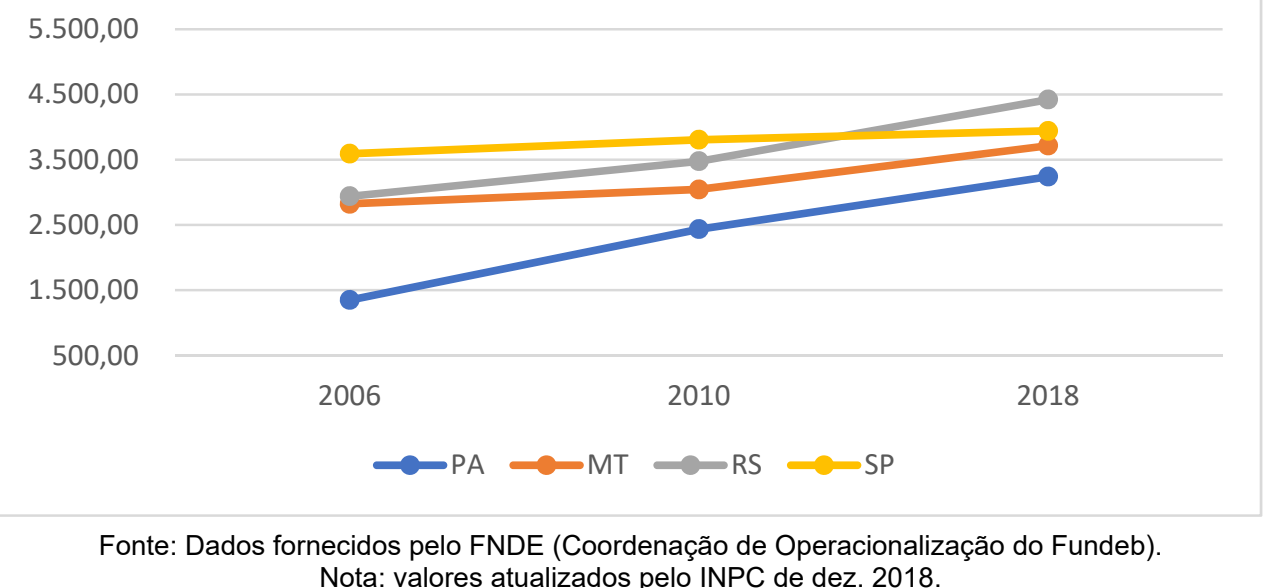

Pará é o estado com VAA equivalente ao mínimo nacional nos três anos. A evolução na direção de aproximação de seu valor com os demais estados é evidente, por exemplo, em 2006 São Paulo teve um VAA 166\% maior que o Pará, proporção que baixou para $56 \%$ em 2010 e para $29 \%$ em 2018. Esses resultados advêm do aumento da complementação da União aos fundos estaduais e da dinâmica de matrículas computadas no Fundeb em cada fundo.

Vale pontuar, ainda, que todos os estados transferem recursos aos municípios. Dados o montante da contribuição dos governos estaduais a cada fundo, maior que $60 \%$ dos recursos, e a representatividade das matrículas estaduais, que não alcança a mesma proporção da contribuição, os estados redistribuem recursos que beneficiam a educação de redes municipais. No ano de 2015, o balanço, para o conjunto dos estados, foi o seguinte (excetuado o DF): contribuição de R\$ 79,6 bilhões, transferência de R\$27,1 bilhões aos municípios, recebimento de $\mathrm{R} \$ 3,8$ bilhões de complementação da União, resultando num retorno no total de $\mathrm{R} \$ 56,3$ bilhões. No mesmo ano, os municípios tiveram um retorno de $\mathrm{R} \$$ 76,2 bilhões - contribuíram com $\mathrm{R} \$ 39,6$ bilhões, receberam $\mathrm{R} \$ 27,1$ bilhões dos estados $\mathrm{e}$ $\mathrm{R} \$ 9,5$ bilhões de complementação da União (ver FNDE, 2016) ${ }^{14}$.

Uma última anotação sobre processos de formulação dos fundos. Ambos foram propostos por emendas à Constituição de iniciativa do Poder Executivo federal. Na sua tramitação no Congresso Nacional, as propostas foram bastante aperfeiçoadas. O Fundeb se

aprofundado, para o período 2007-2014, ver Oliveira, Rodrigues e Souza (2015). Para efeito redistributivo intraestadual, no período 2008-2011, ver Peres et al. (2015).

13 Foram considerados os valores anuais por aluno do Fundeb após o ajuste anual, disponibilizados pela Coordenação de Operacionalização do Fundeb do FNDE.

14 Valores nominais. 
destaca por ter sido concebido contando com o legado de benefícios e de problemas da política prévia (o Fundef) e por ter envolvido participação mais ampla em sua formulação ${ }^{15}$. É de ressaltar, nessa participação, a forte atuação da Campanha Nacional pelo Direito à Educação (NASCIMENTO, 2009).

Feito este resumido retrato dos fundos, serão analisadas na sequência as matrículas da educação básica, elemento que, assim como os recursos, é decisivo para tratar das responsabilidades federativas na oferta e no financiamento da educação nos contextos do Fundeb e do Fundef.

\section{Matrículas na educação básica no período da política de fundos}

A opção foi a de apresentar dados de três anos: 1996, um ano antes da entrada em vigor do Fundef; 2006, último ano do Fundef; 2018, para manter certa coerência com o ano mais recente dos dados apresentados na seção anterior deste artigo. É feita referência ao primeiro período (1996 e 2006) e ao segundo período (2006 e 2018). São pontuadas possibilidades de incidência do Fundef e do Fundeb nos movimentos observados, sem pretensão de explorar e articular a ampla gama de causas intervenientes no movimento de matrículas. A exposição, porventura, poderá suscitar exames da complexidade do ocorrido em diferentes segmentos. Para iniciar, a Tabela 1 traz os registros da educação básica.

Tabela 1 - Matrículas na educação básica, por dependência administrativa Brasil - 1996, 2006 e 2018

\begin{tabular}{c|c|c|c|c|c|c|c}
\hline \multirow{2}{*}{ Ano } & Total & \multicolumn{2}{|c|}{ Estadual } & \multicolumn{2}{c|}{ Municipal } & \multicolumn{2}{c}{ Particular } \\
\cline { 2 - 8 } & $\boldsymbol{n}$ & $\boldsymbol{n}$ & $\%$ & $\boldsymbol{n}$ & $\%$ & $\boldsymbol{n}$ & $\%$ \\
\hline 1996 & 46.916 .772 & 23.365 .283 & $50 \%$ & 17.547 .586 & $37 \%$ & 5.903 .903 & $13 \%$ \\
\hline 2006 & 55.942 .047 & 23.175 .567 & $41 \%$ & 25.243 .156 & $45 \%$ & 7.346 .203 & $13 \%$ \\
\hline 2018 & 48.455 .867 & 15.946 .416 & $33 \%$ & 23.103 .124 & $48 \%$ & 8.995 .249 & $19 \%$ \\
\hline
\end{tabular}

Fonte: Sinopses Estatísticas da Educação Básica, do INEP.

Nota: o total inclui matrículas da rede federal de ensino.

Sobressai o decréscimo de matrículas no ano de 2018 em comparação a 2006 (-13\%), o que comumente é atribuído ao movimento demográfico ocorrido no País. Uma análise mais acurada precisaria levar em conta, contudo, as taxas de escolarização, pois a quantidade de pessoas que não concluiu o ensino fundamental e o ensino médio é alarmante. No setor público fica evidenciada a reversão nas proporções das redes estaduais e municipais. A municipalização - aqui entendida estritamente como aumento de matrículas municipais frente às matrículas estaduais - ocorre tanto no primeiro período (1996-2006) quanto no segundo (2006-2018). No primeiro, foi impulsionada pelo Fundef e pela definição das prioridades dos estados na LDB e na Emenda à Constituição (EC) n. 14/1996, que desencadeou a municipalização da educação infantil (FARENZENA, 2012).

$\mathrm{Na}$ educação infantil (Tabela 2), houve aumento no número de matrículas nos dois períodos, com percentual de $64 \%$ no primeiro período e $25 \%$ no segundo intervalo. O aumento efetivo no primeiro período deve ser ponderado pelo fato de que em 1996 o Censo Escolar não contemplava os registros de matrículas em creche.

15 Sobre a tramitação do Fundef no Congresso Nacional ver Farenzena (2006). Sobre a formulação do Fundeb, consultar Martins (2011) e Machado (2007). 
Tabela 2 - Matrículas na educação infantil, por dependência administrativa Brasil - 1996, 2006 e 2018

\begin{tabular}{c|c|c|c|c|c|c|c}
\hline \multirow{2}{*}{ Ano } & Total & \multicolumn{2}{c|}{ Estadual } & \multicolumn{2}{c|}{ Municipal } & \multicolumn{2}{c}{ Particular } \\
\cline { 2 - 8 } & $\boldsymbol{n}$ & $\boldsymbol{n}$ & $\%$ & $\boldsymbol{n}$ & $\%$ & $\boldsymbol{n}$ & $\%$ \\
\hline 1996 & 4.270 .376 & 759.187 & $18 \%$ & 2.489 .225 & $58 \%$ & 1.019 .487 & $24 \%$ \\
\hline 2006 & 7.016 .095 & 242.979 & $3 \%$ & 4.820 .236 & $69 \%$ & 1.950 .409 & $28 \%$ \\
\hline 2018 & 8.745 .184 & 56.305 & $1 \%$ & 6.262 .879 & $72 \%$ & 2.423 .233 & $28 \%$ \\
\hline \multicolumn{6}{c}{ Fonte: Sinopses Estatísticas da Educação Básica, do INEP. } \\
Nota: o total inclui matrículas da rede federal de ensino.
\end{tabular}

O maior quantitativo em 2018 reflete, notadamente, o incentivo do Fundeb e o reconhecimento da obrigatoriedade da pré-escola na Emenda n. 59/2009 à Constituição. Em todo o período, a baixa cobertura da creche e da pré-escola, frente às metas dos planos nacionais de educação, também é fator que explica o crescimento. É evidenciada a oferta municipalizada (99\% da matrícula pública em 2018) e a municipalização da educação infantil nesses 22 anos, tendo as redes estaduais diminuído acentuadamente a oferta depois que a LDB (de 1996) e a EC n. 14/1996 não incluíram a educação infantil entre as prioridades dos estados. As matrículas da rede particular tiveram mais incremento no segundo período, sendo uma das explicações o fato de que foi ampliado o subsídio público às instituições privadas sem fins lucrativos, estimulado pela possibilidade do cômputo das suas matrículas no âmbito do Fundeb (em 2018 foram consideradas em torno de 697 mil matrículas de instituições privadas subsidiadas de educação infantil no Fundeb).

$\mathrm{Na}$ educação infantil, conforme dados do INEP (2018), a maior taxa de crescimento em todo o período foi na creche, mas persiste, neste segmento, expressivo déficit de cobertura em 2016, a taxa de atendimento das crianças de zero a três anos de idade ficou em $32 \%$, faltando muito para chegar à meta de $50 \%$ fixada no Plano Nacional de Educação (PNE) 20142024 (Lei n. 13.005/2014). Na pré-escola, a meta do PNE de universalização, estabelecida para 2016 não foi alcançada e naquele ano a taxa de escolarização líquida foi de $91,5 \%$.

Tabela 3 - Matrículas no ensino fundamental, por dependência administrativa Brasil - 1996, 2006 e 2018

\begin{tabular}{c|c|c|c|c|c|c|c}
\hline \multirow{2}{*}{ Ano } & Total & \multicolumn{2}{|c|}{ Estadual } & \multicolumn{2}{c|}{ Municipal } & \multicolumn{2}{c}{ Particular } \\
\cline { 2 - 8 } & $\boldsymbol{n}$ & $\boldsymbol{n}$ & $\boldsymbol{\%}$ & $\boldsymbol{n}$ & $\boldsymbol{\%}$ & $\boldsymbol{n}$ & $\%$ \\
\hline 1996 & 33.131 .270 & 18.468 .772 & $56 \%$ & 10.921 .037 & $33 \%$ & 3.707 .897 & $11 \%$ \\
\hline 2006 & 33.282 .663 & 11.825 .112 & $36 \%$ & 17.964 .543 & $54 \%$ & 3.467 .977 & $10 \%$ \\
\hline 2018 & 27.183 .970 & 7.062 .312 & $26 \%$ & 15.427 .206 & $57 \%$ & 4.672 .131 & $17 \%$ \\
\hline
\end{tabular}

Fonte: Sinopses Estatísticas da Educação Básica, do INEP.

Nota: o total inclui matrículas da rede federal de ensino.

O ensino fundamental (Tabela 3) era a etapa obrigatória da educação até a promulgação da Emenda à Constituição n. 59/2009. Já tinha cobertura relativamente maior antes que o Fundef entrasse em vigor, mas esta foi acentuada de 1996 e 2006 com o fomento oferecido pelo Fundef. Esse mesmo Fundo estimulou a municipalização, sendo esta um objetivo da política, reconhecido pelo Poder Executivo à época de tramitação da Proposta de Emenda Constitucional que deu origem à EC n. 14/1996 (Farenzena, 2006). É de ressalvar que, em 
alguns estados brasileiros, processos de municipalização ocorreram antes da formulação do Fundef, ou, junto às incitações ligadas ao Fundef, advieram de outras inspirações ${ }^{16}$.

Mesmo que as taxas de escolarização líquida no ensino fundamental sejam as mais elevadas das três etapas da educação básica, apenas 75,9\% dos jovens de 16 anos tinham o ensino fundamental completo em 2017, longe da meta de $95 \%$ estabelecida no Plano Nacional de Educação 2014-2024; das crianças de seis a 14 anos de idade, 597 mil não cursavam e nem haviam concluído o ensino fundamental no mesmo ano (INEP, 2018).

Nas matrículas do ensino médio (Tabela 4) encontra-se a característica de oferta estadualizada, a qual aumentou no intervalo de tempo considerado. As matrículas cresceram no primeiro período (55\%), porém, de 2006 para 2018 foram mais de um milhão a menos (13\%). Entre 1996 e 2006, na vigência do Fundef, a demanda pelo ensino médio aumentou, principalmente em decorrência da ampliação da cobertura do ensino fundamental. Os estados, com o dever de priorizar essa etapa, ampliaram a oferta, muitos deles com mais capacidade de fazê-lo face à municipalização do ensino fundamental e da pré-escola. Em que pese o ensino médio ter sido contemplado na política de fundos no período seguinte, o decréscimo se deve, entre outros, a efeitos da transição demográfica, da não conclusão do ensino fundamental, da evasão e de condições de oferta insuficientes para atender necessidades específicas, tais como a localização e os turnos de funcionamento das escolas e a conciliação entre trabalho e estudo.

Segundo dados do INEP (2018), frequentavam a escola ou já tinham concluído o ensino médio 91,3 dos adolescentes de 15 a 17 anos de idade em 2017. Com isso, a meta de universalização traçada no PNE 2014-2024 para 2016 não fora atingida - eram 907 mil adolescentes de 15 a 17 anos de idade que não estavam frequentando a escola e tampouco haviam concluído o ensino médio. A taxa líquida de escolarização da mesma faixa etária ficou em $70,1 \%$ em 2017 , o que evidenciava o enorme desafio de atingir a meta do PNE: $85 \%$ em 2024.

Tabela 4 - Matrículas no ensino médio, por dependência administrativa - Brasil - 1996, 2006 e 2018

\begin{tabular}{r|c|r|c|c|c|c|c}
\hline \multirow{2}{*}{ Ano } & Total & \multicolumn{2}{|c|}{ Federal } & \multicolumn{2}{c|}{ Estadual } & \multicolumn{2}{c}{ Particular } \\
\cline { 2 - 8 } & $\boldsymbol{n}$ & $\boldsymbol{n}$ & $\boldsymbol{1}$ & $\boldsymbol{n}$ & $\boldsymbol{\%}$ & $\boldsymbol{n}$ & $\boldsymbol{\%}$ \\
\hline 1996 & 5.739 .077 & 113.091 & $2 \%$ & 4.137 .324 & $72 \%$ & 1.176 .519 & $21 \%$ \\
\hline 2006 & 8.906 .820 & 67.650 & $1 \%$ & 7.584 .391 & $85 \%$ & 1.068 .734 & $12 \%$ \\
\hline 2018 & 7.709 .929 & 209.358 & $3 \%$ & 6.527 .074 & $85 \%$ & 932.037 & $12 \%$ \\
\hline
\end{tabular}

Fonte: Sinopses Estatísticas da Educação Básica, do INEP.

Nota: o total inclui matrículas das redes municipais de ensino.

Na educação de jovens e adultos (EJA), cujas matrículas são apresentadas na Tabela 5, manteve-se o predomínio da oferta nas redes estaduais de ensino. Os dados agrupam ensino fundamental e ensino médio, mas é importante pontuar que o ensino fundamental é mais municipalizado (63\%), enquanto no ensino médio a proporção estadual é de $88 \%$. Um dos movimentos ocorridos foi a queda na proporção da esfera particular, mais acentuada na EJA/ensino fundamental entre 1996 e 2006 . O decréscimo no quantitativo de matrículas entre 2006 e 2018 se deve à redução na EJA/ensino fundamental, pois na EJA/ensino médio houve um pequeno aumento, de $6 \%$. As matrículas da EJA/ensino fundamental não eram

16 Dentre outros estudos, podem ser consultados, a respeito de processos peculiares de municipalização, não restritos a efeitos do Fundef nos estados: Albuquerque (2005); Gutierrez (2005); Martins (2003), Santos (2003). 
computadas para a redistribuição de recursos do Fundef, mesmo assim houve acréscimo de 64\% entre 1996 e 2006. No Fundeb, a EJA das duas etapas é contemplada, todavia, sempre com os mais baixos fatores de ponderação, apenas passando de 0,7 para 0,8 . Outro limite é a regra contida no Art. 11 da lei regulamentadora do Fundeb (Lei n. 11.494/2007): "[...] a apropriação de recursos em função das matrículas na modalidade de educação de jovens e adultos [...] observará, em cada Estado e no Distrito Federal, percentual de até 15\% (quinze por cento) dos recursos do Fundo respectivo". Ou seja, se houvesse crescimento expressivo de matrículas na modalidade, somente uma parte delas seria computada para a redistribuição de recursos do Fundeb.

Tabela 5 - Matrículas na educação de jovens e adultos, por dependência administrativa Brasil - 1996, 2006 e 2018

\begin{tabular}{c|c|c|c|c|c|c|c}
\hline \multirow{2}{*}{ Ano } & Total & \multicolumn{2}{|c|}{ Estadual } & \multicolumn{2}{c|}{ Municipal } & \multicolumn{2}{c}{ Particular } \\
\cline { 2 - 8 } & $\boldsymbol{n}$ & $\boldsymbol{n}$ & $\boldsymbol{\%}$ & $\boldsymbol{n}$ & $\%$ & $\boldsymbol{n}$ & $\%$ \\
\hline 1996 & 2.476 .554 & 1.565 .229 & $63 \%$ & 520.104 & $21 \%$ & 390.936 & $16 \%$ \\
\hline 2006 & 4.861 .390 & 2.553 .819 & $53 \%$ & 2.126 .552 & $44 \%$ & 179.816 & $4 \%$ \\
\hline 2018 & 3.545 .988 & 1.956 .621 & $55 \%$ & 1.354 .712 & $38 \%$ & 221.632 & $6 \%$ \\
\hline
\end{tabular}

Nota: o total inclui matrículas da rede federal de ensino.

Os dados, mais acima comentados, quanto à escolarização ou escolaridade da população nos ensinos fundamental e médio provam que a ampliação da EJA é demanda recorrente e concreta e que sua oferta precisará ser valorizada na reformulação do Fundeb. Acrescentam-se alguns dados de 2016: a média de escolaridade dos jovens entre 18 e 29 anos era de 10,2 anos, distante da meta de 12 anos projetada no PNE 2014-2024; a taxa de analfabetismo funcional era de $16,6 \%$ e a meta do PNE para 2024 é de baixar para $9,2 \%$ (INEP, 2018).

$\mathrm{Na}$ educação especial (Tabela 6) ocorre crescimento em todo o período, no total e nas duas redes públicas. Em 2006, a matrícula teve aumento de quase três vezes e meia em relação a 1996. Em 2018, 69\% a mais do que em 2006. Nas escolas particulares o atendimento aumentou bastante no primeiro período, mas decresceu $27 \%$ se cotejados 2018 e 2006.

Tabela 6 - Matrículas na educação especial, por dependência administrativa - Brasil - 2006 e 2018

\begin{tabular}{r|r|r|r|r|r|r|r}
\hline \multirow{2}{*}{ Ano } & Total & \multicolumn{2}{c|}{ Estadual } & \multicolumn{2}{c|}{ Municipal } & \multicolumn{2}{c}{ Particular } \\
\cline { 2 - 8 } & $\boldsymbol{n}$ & $\boldsymbol{n}$ & $\%$ & $\boldsymbol{n}$ & \multicolumn{1}{c}{$\%$} & $\boldsymbol{n}$ & $\%$ \\
\hline 1996 & 201.142 & 90.688 & $45 \%$ & 29.591 & $15 \%$ & 79.928 & $40 \%$ \\
\hline 2006 & 700.624 & 174.985 & $25 \%$ & 265.053 & $38 \%$ & 259.469 & $37 \%$ \\
\hline 2018 & 1.181 .276 & 355.783 & $30 \%$ & 631.339 & $53 \%$ & 189.192 & $16 \%$ \\
\hline \multicolumn{6}{c}{ Fonte: Sinopses Estatísticas da Educação Básica, do INEP, dos anos selecionados. } \\
Nota: o total inclui matrículas da rede federal de ensino.
\end{tabular}

Ocorreu municipalização, dada a predominância da oferta municipal no ensino fundamental e na educação infantil. O período foi de afirmação do direito à educação das pessoas com deficiência, transtornos globais do desenvolvimento e altas habilidades, com a edição da LDB, em 1996, e o reconhecimento da prioridade à educação especial inclusiva em normas e políticas nacionais num momento que coincidiu com a implantação do Fundeb; essa prioridade explica, pelo menos em parte, a queda no número de matrículas na rede particular no segundo período, pois grande parte das instituições oferecia atendimento exclusivamente 
especializado. Com o Fundeb, é possível dizer que houve valorização da educação especial por meio da atribuição de ponderações relativamente mais elevadas das suas matrículas e valorização da educação especial inclusiva com o cômputo de dupla matrícula dos educandos que fazem parte do público alvo da educação especial: nas classes comuns do ensino regular público e no atendimento educacional especializado. Das matrículas de $2018,86 \%$ eram em classes comuns; a rede particular concentrava o atendimento especializado, com $74 \%{ }^{17}$.

\section{Comentários finais}

No Brasil, o governo da educação, a organização jurídico-política do setor, combina autonomia - coerente com a autonomia constitucional conferida aos entes federativos - e interdependência, com definições de prioridades de cada nível de governo e de atuação conjunta por meio de colaboração entre os sistemas de ensino e de cooperação federativa. No artigo, foram caracterizados aspectos do federalismo na educação no que concerne à oferta e ao financiamento.

No financiamento, foram pontuadas algumas semelhanças e diferenças entre Fundef e Fundeb, enfatizando-se singularidades da participação das esferas de governo nesses fundos. O Fundeb foi objeto de maior atenção, mostrando-se seus efeitos redistributivos mais acentuados em relação ao Fundo anterior e a evolução negativa no volume de seus recursos a partir de 2015 , sem que a complementação da União tenha ultrapassado o mínimo de $10 \%$ dos recursos estaduais, municipais e do DF.

Em relação às matrículas da educação básica, é de frisar a sua diminuição entre a década de 2000 e a década seguinte. Das etapas e modalidades analisadas, ensino fundamental, ensino médio e EJA sofreram redução, enquanto educação infantil e educação especial tiveram acréscimos significativos. Da distribuição entre as redes públicas, na vigência da política de fundos observou-se: municipalização da educação infantil, do ensino fundamental, da EJA/ensino fundamental e da educação especial; manutenção da oferta estadualizada do ensino médio e da EJA/ensino médio.

Como medida de análise das matrículas frente aos requerimentos da garantia do direito à educação foram contrastadas algumas metas de escolarização do PNE 2014-2024 com dados da efetiva escolarização da população. Nas três etapas da educação básica e na modalidade EJA foi possível assinalar déficits que, ao que tudo indica, não serão superados até 2024, deixando tarefas por fazer no plano nacional da década seguinte, ainda mais considerando-se as desigualdades marcantes nos recortes regional, de renda, raça/cor e do local de residência (urbano-rural, centro-periferia) da população.

A implantação do Fundeb em caráter permanente, tema da agenda de deliberação da política educacional do País na atualidade, poderá ser decisiva para avançarmos no cumprimento das metas do atual e do futuro PNE. Os termos da cooperação federativa na educação fazem parte do debate e sua redefinição é um dos elementos decisivos para promoção de maior justiça na educação ${ }^{18}$. No cenário da reformulação do Fundeb encontram-

17 Não foram comentados dados de acompanhamento da meta 04 do PNE pelo último Relatório do INEP (2018) em função de terem sido usados dados de 2010.

18 A respeito da promoção de maior justiça federativa nas regras do Fundeb permanente previsto na EC $n$. 15/2015, em tramitação na Câmara dos Deputados, consultar Fineduca (2020a; 2020b; 2020c) e Fineduca e CNDE (2020). 
se, mais recentemente, incertezas oriundas das crises econômica e política de 2020, diante das quais é exigida a atuação ainda mais forte e articulada dos setores engajados na causa da democratização da educação pública.

\section{Referências}

AFONSO, José Roberto; CASTRO, Kleber Pacheco de. Consolidação da carga tributária bruta de 2018. Jota, São Paulo, 2019. Disponível em: <https://www.jota.info/wpcontent/ uploads/2020/01/carga-tributaria-bruta-de-2018.pdf>. Acesso em: 04 maio 2020.

ALBUQUERQUE, Francisco Carlos Araújo. Estado e municipalização do ensino no Ceará. 0 Público e o Privado, n. 5, p. 43-59, jan./jun. 2005.

ARAUJO, Gilda Cardoso de. Direito à educação básica: a cooperação entre os entes federados. Revista Retratos da Escola, Brasília, v. 4, n. 7, p. 231-243, jul./dez. 2010.

BEZES, Philipe; PALIER, Bruno. Trajectoire de réformes: comment rétracer les processos de transformation des institutions. Revue Française des Sciences Politiques, v. 68, n. 6, p. 1083-1112, 2018.

BRASIL. Constituição da República Federativa do Brasil de 1988 [com redação atualizada]. Diário Oficial da União, Brasília, DF, 5 de outubro de 1988.

BRASIL. Lei $n^{\circ}$ 9.394, de 20 de dezembro de 1996. Estabelece as diretrizes e bases da educação nacional. Diário Oficial da União, Brasília, 1996a.

BRASIL. Lei no 9.424, de 24 de dezembro de 1996. Dispõe sobre o Fundo de Manutenção e Desenvolvimento do Ensino Fundamental e de Valorização do Magistério [...]. Diário Oficial da União, Brasília, 1996b.

BRASIL. Lei $n^{\circ}$ 11.494, de 20 de junho de 2007. Regulamenta o Fundo de Manutenção e Desenvolvimento da Educação Básica e de Valorização dos Profissionais da Educação FUNDEB [...]. Diário Oficial da União, Brasília, 2007.

BRASIL. Lei n 13.005, de 13 de junho de 2014. Aprova o Plano Nacional de Educação. Diário Oficial da União, Brasília, 2014.

FARENZENA, Nalú. A política de financiamento da educação básica: rumos da legislação brasileira. Porto Alegre: Editora da UFRGS, 2006.

FARENZENA, Nalú. Panoramas do gasto público e da oferta de educação básica na perspectiva da esfera estadual. Fineduca - Revista de Financiamento da Educação, Porto Alegre, v. 2, n. 6, 2012.

FARENZENA, Nalú. Equiparação nas capacidades de financiamento da educação básica no âmbito do Fundeb: uma exploração. In: ENCONTRO DA ASSOCIAÇÃO NACIONAL DE PESQUISA EM FINANCIAMENTO DA EDUCAÇÃO, 2., 2014, Curitiba. Anais... Curitiba, 2014. p. 81-93.

FARENZENA, Nalú. Capacidades de financiamento da educação básica no Fundeb: uma costura. In: FERNANDES, Maria Dilnéia Espíndola; PINTO, José Marcelino de Rezende; GOUVEIA, Andréa Barbosa (Org.). Financiamento da educação no Brasil: os desafios de gastar $10 \%$ do PIB em dez anos. Campo Grande: Oeste, 2015. p. 83-107. 
FARENZENA, Nalú. Organização da educação nacional: tópicos. Porto Alegre: UFRGS/Faced, versão 2018. (texto didático, digitado).

FARENZENA, Nalú; LUCE, Maria Beatriz. Financiamento da educação e responsabilidades federativas: 25 anos de agenda constituinte. Revista Brasileira de Política e Administração da Educação, Goiânia, v. 29, n. 2, p. 263-281, maio/ago. 2013.

FARENZENA, Nalú; LUCE, Maria Beatriz. Políticas Públicas de Educação no Brasil: reconfigurações. In: MADEIRA, Lígia Mori. Avaliação de políticas públicas. Porto Alegre: UFRGS/CEGOV, 2014. p. 195-215.

FINEDUCA. Associação Nacional de Pesquisa em Financiamento da Educação. Por um Fundeb mais justo e com maior compromisso da União. São Paulo, 2020a. Disponível em: <http://fineduca.org.br/wp-content/uploads/2020/03/Fineduca_Nota_Por-um-Fundebmais-justo_01.03.2020.pdf>. Acesso em: 03 mar. 2020.

FINEDUCA. Associação Nacional de Pesquisa em Financiamento da Educação. Porque o salário-educação não pode ser fonte da complementação da União ao Fundeb. São Paulo, 2020b. Disponível em: <https://fineduca.org.br/2020/03/27/por-que-o-salarioeducacao-nao-pode-ser-fonte-da-complementacao-da-uniao-ao-fundeb/>. Acesso em: 02 mar. 2020.

FINEDUCA. Associação Nacional de Pesquisa em Financiamento da Educação. Em defesa de novos recursos para complementação da União ao Fundeb. São Paulo, 2020c. Disponível em: <https://fineduca.org.br/2020/04/13/em-defesa-de-novos-recursos-paracomplementacao-da-uniao-ao-fundeb/>. Acesso em: 02 abr. 2020.

FINEDUCA. Associação Nacional de Pesquisa em Financiamento da Educação; CNDE. Campanha Nacional pelo Direito à Educação. Atenção: é preciso proteger o financiamento da educação básica dos prejuízos da crise econômica! São Paulo, 2020d. Disponível em: $<$ https://fineduca.org.br/wp-content/uploads/2020/05/20200507_Nota_queda_recei tas_final.pdf>. Acesso em: 04 maio 2020.

FNDE. Fundo Nacional de Desenvolvimento da Educação. Distribuição do Fundeb por estado - total 2015. FNDE, 2016. Disponível em: <http://www.fnde.gov.br/index.php /financiamento/fundeb/area-para-gestores/dados-estatisticos/item/10710-repasseconsolidado-anos-anteriores>. Acesso em: 03 maio 2020.

GUTIERREZ, Dalva Valente Guimarães. A política de municipalização do ensino no Estado do Pará e suas relações com a reforma do Estado. 2005. 251 f. Dissertação (Mestrado em Educação) - Instituto de Ciências da Educação, Universidade Federal do Pará, Belém, 2005.

INEP. Instituto Nacional de Estudos e Pesquisas Educacionais Anísio Teixeira (2018). Relatório do segundo ciclo de monitoramento das Metas do Plano Nacional de Educação - 2018. Brasília: Inep, 2018.

MACHADO, Maria Goreti Farias. A proposta de Fundeb do Executivo federal: interlocuções na formulação da política. 2007. Dissertação (Mestrado em Educação) - Programa de PósGraduação em Educação, Universidade Federal do Rio Grande do Sul, Porto Alegre, 2007. 
MARTINS, Ângela Maria. Uma análise da municipalização do ensino no Estado de São Paulo. Cadernos de Pesquisa, São Paulo, n. 120, p. 221-238, nov. 2003.

MARTINS, Paulo de Sena. Fundeb: federalismo e regime de colaboração. Campinas: Autores Associados, 2011.

NASCIMENTO, Iracema. "Direito à Educação começa no berço e é pra toda a vida". A atuação da Campanha Nacional pelo Direito à Educação na criação do Fundo da Educação Básica. Brasil, fev. 2009. Disponível em: <https://media.campanha.org.br/acervo/docu mentos/fundeb_AA_portugues.pdf>. Acessado em: 03 jul. 2019.

OLIVEIRA, Mariano Laio; RODRIGUES, Elenita Gonçalves; SOUZA, Marcelo Lopes de. Efeito supletivo do Fundeb via complementação da União: análise das receitas dos valores anuais por aluno (VAA) efetivos (2007 a 2014). Brasília: Instituto Nacional de Estudos e Pesquisas Educacionais Anísio Teixeira, 2015.

PERES, Alexandre José de Souza; SOUZA, Marcelo Lopes de; ALVES, Fabiana de Assis; RODRIGUES, Elenita Gonçalves. Efeito redistributivo intraestadual do Fundeb: uma análise a partir de variáveis financeiras, socioeconômicas e educacionais dos municípios. Brasília: Instituto Nacional de Estudos e Pesquisas Educacionais Anísio Teixeira, 2015.

SANTOS, Jussara Maria Tavares Puglielli. O processo de municipalização no Estado do Paraná. Educar em Revista, Curitiba, n. 22, p. 257-279, 2003.

STN. Secretaria do Tesouro Nacional. Fundeb 2018. Brasília, 2018. Disponível em: <http://www.tesouro.fazenda.gov.br/transferencias-constitucionais-e-legais>. Acesso em: 03 maio 2020.

TANNO, Cláudio Riyudi. Universalização, qualidade e equidade na alocação de recursos do Fundo de Manutenção e Desenvolvimento da Educação Básica e de Valorização dos Profissionais da Educação (FUNDEB): proposta de aprimoramento para a implantação do Custo Aluno Qualidade (CAQ). Brasília: Câmara dos Deputados; CONOF; Estudo Técnico n. 24/2017, out. 2017.

TCU. Tribunal de Contas da União. Painel dos precatórios do Fundef. Brasília, 2020. Disponível em: <https://portal.tcu.gov.br/imprensa/noticias/tcu-divulga-painel-cominformacoes-sobre-os-precatorios-do-fundef.htm>. Acesso em: 02 maio 2020.

\section{Apêndice}

\section{Referências dados de Receitas do Fundef (2006) e Fundeb (2007-2018)}

Receitas do Fundef, por estado, em 2006

BRASIL. Secretaria do Tesouro Nacional. Fundef União - valores distribuídos aos estados [2006]. Estatísticas: Transferências constitucionais - relatórios consolidados por unidade da federação. Brasília, 2006a. Disponível em: <http://www.tesouro.fazenda.gov.br/est atistica/est_estados.asp>. Acesso em: 18 out. 2012.

BRASIL. Secretaria do Tesouro Nacional. Fundef União - valores distribuídos aos municípios [2006]. Estatísticas: Transferências constitucionais - relatórios consolidados por 
A Política de Fundos e as Responsabilidades Federativas pela Oferta de Educação Básica

unidade da federação. Brasília, 2006b. Disponível em: <http://www.tesouro.fazenda.gov. br/estatistica/est_estados.asp>. Acesso em: 18 out. 2012.

BRASIL. Ministério da Fazenda. Portaria $n^{\circ}$ 40, de 03 de março de 2006. Complementação da União ao Fundef em 2006. Brasília, 2006c. Disponível em: <http://www.fnde.gov .br/index.php/fundef-legislacao>. Acesso em: 18 out. 2012.

Receitas do Fundeb, por estado, de 2007 a 2018, e valor mínimo nacional do Fundeb pós ajuste anual

BRASIL. Ministério da Educação. Portaria $n^{\circ} 1.462$, de $1^{\circ}$ de dezembro de 2008. Divulga demonstrativo final da distribuição dos recursos do Fundeb do exercício de 2007. Brasília: MEC, 2008. Disponível em: <http://www.fnde.gov.br/index.php/fundeb-legislacao>. Acesso em: 02 out. 2012.

BRASIL. Ministério da Educação. Portaria $n^{\circ}$ 386, de 17 de abril de 2009. Divulga demonstrativo final da distribuição dos recursos do Fundeb do exercício de 2008. Brasília: MEC, 2009. Disponível em: <http://www.fnde.gov.br/index.php/fundeb-legislacao>. Acesso em: Acesso em: 02 out. 2012.

BRASIL. Ministério da Educação. Portaria n 1.174, de 23/9/2010. Retifica o demonstrativo do ajuste anual do FUNDEB/2009. Brasília: MEC, 2010. Disponível em <http://www.fnde.gov .br/index.php/fundeb-legislacao>. Acesso em: 02 out. 2012.

BRASIL. Ministério da Educação. Portaria $n^{\circ} 380$, de 06/4/2011. Divulga demonstrativo final da distribuição dos recursos do Fundeb do exercício de 2010. Brasília: MEC, 2011. Disponível em: <http://www.fnde.gov.br/index.php/fundeb-legislacao>. Acesso em: 02 out. 2012.

BRASIL. Ministério da Educação. Portaria n 437, de 20 de abril de 2012 [inclui Anexo]. Divulga demonstrativo final da distribuição dos recursos do Fundeb do exercício de 2011. Brasília: MEC, 2012. Disponível em: <http://www.fnde.gov.br/index.php/fundeb-legislacao>. Acesso em: 02 out. 2012.

BRASIL. Ministério da Educação. Portaria n 344, de 24 de abril de 2013. Dispõe sobre o ajuste anual da distribuição dos recursos do Fundo de Manutenção e Desenvolvimento da Educação Básica e de Valorização dos Profissionais da Educação (Fundeb), no exercício de 2012. Brasília: MEC, 2013. Disponível em: <http://www.fnde.gov.br/financiament o/fundeb/fundeb-legislacao/item/4427-portaria-mec-n\%C2\%B0-344,-de-24-de-abril-de2013>. Acesso em: 02 maio 2013.

BRASIL. Ministério da Educação. Portaria $n^{\circ}$ 364, de 28 de abril de 2014. [ajuste anual da distribuição dos recursos do Fundo de Manutenção e Desenvolvimento da Educação Básica e de Valorização dos Profissionais da Educação (Fundeb), no exercício de 2013]. Brasília: MEC, 2014. Disponível em: <https://www.fnde.gov.br/index.php/acesso-a-informacao/ institucional/legislacao/item/5386-portaria-n\%C2\%BA-364,-de-28-de-abril-de-2014>. Acesso em: 02 maio 2014.

BRASIL. Ministério da Educação. Portaria n 317, de 27 de março de 2015. Divulga o Demonstrativo de Ajuste Anual da Distribuição dos Recursos do Fundo de Manutenção e Desenvolvimento da Educação Básica e de Valorização dos Profissionais da Educação Fundeb do exercício de 2014. Brasília: MEC, 2015. Disponível em: <http://www. 
fnde.gov.br/acesso-a-informacao/institucional/legislacao/item/6334-portaria-n\%C2\%BA-317,de-27-de-mar\%C3\%A7o-de-2015>. Acesso em: 02 abr. 2015.

BRASIL. Ministério da Educação. Portaria $n^{\circ}$ 426, de 11 de maio de 2016. Divulga o Demonstrativo de Ajuste Anual da Distribuição dos Recursos do Fundo de Manutenção e Desenvolvimento da Educação Básica e de Valorização dos Profissionais da Educação Fundeb do exercício de 2015. Brasília: MEC, 2016. Disponível em: $<$ https://www.fnde.gov.br/index.php/acesso-a-informacao/institucional/legislacao/item/8921portaria-mec-n\%C2\%BA-426,-de-11-de-maio-de-2016>. Acesso em: 02 maio 2016.

BRASIL. Ministério da Educação. Portaria $n^{\circ}$ 565, de 20 de abril de 2017. Divulga o Demonstrativo de Ajuste Anual da Distribuição dos Recursos do Fundo de Manutenção e Desenvolvimento da Educação Básica e de Valorização dos Profissionais da Educação Fundeb do exercício de 2016. Brasília: MEC, 2017. Disponível em: <https://www .fnde.gov.br/index.php/acesso-a-informacao/institucional/legislacao/item/11932-portariamec-n-565-de-20-de-abril-de-2017>. Acesso em: 02 maio 2017.

BRASIL. Ministério da Educação. Portaria $n^{\circ}$ 385, de 26 de abril de 2018. Divulga o Demonstrativo de Ajuste Anual da Distribuição dos Recursos do Fundo de Manutenção e Desenvolvimento da Educação Básica e de Valorização dos Profissionais da Educação Fundeb do exercício de 2017. Brasília: MEC, 2018. Disponível em: http://www.in. gov.br/materia/-/asset_publisher/Kujrw0TZC2Mb/content/id/12152343/do1-2018-04-27portaria-n-385-de-26-de-abril-de-2018-12152339. Acessado em: maio de 2018.

BRASIL. Ministério da Educação. Portaria $n^{\circ}$ 946, de 29 de abril de 2019. Divulga o Demonstrativo de Ajuste Anual da Distribuição dos Recursos do Fundo de Manutenção e Desenvolvimento da Educação Básica e de Valorização dos Profissionais da Educação Fundeb do exercício de 2018. Brasília: MEC, 2019. Disponível em: <https://www.fnde. gov.br/index.php/acesso-a-informacao/institucional/legislacao/item/12858-portarian\%C2\%BA-207,-de-22-de-abril-de-2019>. Acesso em: 02 maio 2019.

Nalú Farenzena é doutora em Educação. Professora Titular da Faculdade de Educação da Universidade Federal do Rio Grande do Sul.

ORCID: http://orcid.org/0000-0003-2582-5925

E-mail: nalu.farenzena@ufrgs.br 


\section{Editores do volume 10}

Márcia Aparecida Jacomini - Universidade Federal de São Paulo, Brasil

José Marcelino de Rezende Pinto - Universidade de São Paulo, Brasil

\section{Comitê Editorial}

Nalú Farenzena - Universidade Federal do Rio Grande do Sul, Brasil

Juca Gil - Universidade Federal do Rio Grande do Sul, Brasil

Theresa Adrião - Universidade Estadual de Campinas, Brasil

Ângelo Ricardo de Souza - Universidade Federal do Paraná, Brasil

\section{Conselho Editorial}

\section{Alejandro Morduchowicz}

Universidad Pedagógica, Provincia de Buenos Aires, Argentina

Andréa Barbosa Gouveia

Universidade Federal do Paraná, Brasil

Fernanda Saforcada

Universidade de Buenos Aires, Argentina

Jacques Velloso

Universidade de Brasília, Brasil

João Monlevade

Senado Federal, Brasil

Jorge Abrahão de Castro

Instituto de Pesquisa Econômica Aplicada / IPEA, Brasil

Lisete Regina Gomes Arelaro

Universidade de São Paulo, Brasil

Luis Carlos Sales

Universidade Federal do Piauí, Brasil

Luiz de Sousa Junior

Universidade Federal da Paraíba, Brasil

Luiz Fernandes Dourado

Universidade Federal de Goiás, Brasil

Magna França

Universidade Federal do Rio Grande do Norte, Brasil

Marcos Edgar Bassi

Universidade Federal de Santa Catarina, Brasil

Maria Angélica Pedra Minhoto

Universidade Federal de São Paulo, Brasil

Maria Beatriz Luce

Universidade Federal do Rio Grande do Sul, Brasil

Maria Dilnéia Espíndola Fernandes

Universidade Federal de Mato Grosso do Sul, Brasil

Nelson Cardoso do Amaral

Universidade Federal de Goiás, Brasil

Nicholas Davies

Universidade Federal Fluminense, Brasil

Robert E. Verhine

Universidade Federal da Bahia, Brasil

Romualdo Portela de Oliveira

Universidade de São Paulo, Brasil

Rosana Gemaque Rolim

Universidade Federal do Pará, Brasil

Rubens Barbosa de Camargo

Universidade de São Paulo, Brasil

Theresa Adrião

Universidade Estadual de Campinas, Brasil

Tristan McCowan

University of London, Reino Unido

Vera Jacob

Universidade Federal do Pará, Brasil

Vera Peroni

Universidade Federal do Rio Grande do Sul, Brasil

Vitor Henrique Paro

Universidade de São Paulo, Brasil

\section{Equipe editorial}

Apoio ao Comitê Editorial: Caio Cabral da Silva

Diagramação, Revisão de português e normalização: Edson Leonel de Oliveira

Revisão de inglês: Sabrina Ferreira

Fineduca - Revista de Financiamento da Educação

Associação Nacional de Pesquisa em

Financiamento da Educação

e-mail: revista.fineduca@gmail.com | site: http://seer.ufrgs.br/fineduca 